\title{
Regional drought assessment using a distributed hydrological model coupled with Standardized Runoff Index
}

\author{
HONGREN SHEN, FEI YUAN, LILIANG REN, MINGWEI MA, HAO KONG \& \\ RUI TONG
}

State Key Laboratory of Hydrology-Water Resources and Hydraulic Engineering, College of Hydrology and Water Resources, Hohai University, No.1 Xikang Road, Nanjing, 210098, China

fyuan@hhu.edu.cn

\begin{abstract}
Drought assessment is essential for coping with frequent droughts nowadays. Owing to the large spatio-temporal variations in hydrometeorology in most regions in China, it is very necessary to use a physically-based hydrological model to produce rational spatial and temporal distributions of hydrometeorological variables for drought assessment. In this study, the large-scale distributed hydrological model Variable Infiltration Capacity (VIC) was coupled with a modified standardized runoff index (SRI) for drought assessment in the Weihe River basin, northwest China. The result indicates that the coupled model is capable of reasonably reproducing the spatial distribution of drought occurrence. It reflected the spatial heterogeneity of regional drought and improved the physical mechanism of SRI. This model also has potential for drought forecasting, early warning and mitigation, given that accurate meteorological forcing data are available.
\end{abstract}

Key words variable infiltration capacity; standardized runoff index; Weihe River basin; drought assessment; spatiotemporal drought analysis

\section{INTRODUCTION}

Droughts are the most devastating meteorological hazards of the 20th century, having extensive coverage and significant adverse impacts on regional agriculture, water resources and environment. Droughts are also one of the costliest natural disasters in the world, causing an average \$6-\$8 billion in global damages annually and affecting many more people than other disasters (Wilhite, 2000). Therefore, rationally monitoring, forecasting and characterizing droughts is of great importance in water resources management and disaster mitigation.

The simplest and most effective method to assess drought is to use drought indices, which are quantitative measures that characterize drought levels by assimilating data from related variables into a single numerical value (Zargar et al., 2011). According to the various kinds of drought definitions, drought indices can be grouped as meteorological indices, agricultural indices, hydrological indices and socio-economic indices (Yuan et al., 2004). However, almost all the drought indices use precipitation either individually or in combination with other variables. Owing to the lag-effect between meteorological and hydrological drought, and the intensified human activities that may directly cause droughts, for example, excessive water use, hydrological conditions should be taken into consideration for drought assessment.

Hydrological processes, which determine the seasonal lags in the influence of climate on streamflow, were quantified by the standardized index algorithm in this study. The multi-temporal and spatially distributed Standardized Runoff Index (SRI) were reconstructed in the Weihe River basin, northwest China. Streamflow is a key input for hydrological drought indices. However, direct measurement of streamflow is only available at the point scale or mosaic scale. Therefore, streamflow was not applicable for assessing droughts on large spatio-temporal scales until the rapid development of distributed hydrological models, which give physically and spatially based hydrological variables. In this study, the variable infiltration capacity (VIC) model was used to simulate hydrological processes in the Weihe River basin, a drought-prone area in Northwest China. Then the modified SRI was calculated by using the VIC simulated runoff for regional drought evolution analysis. The results based on this coupled model may provide some scientific support for fighting against droughts. 


\section{DATA AND METHODOLOGY}

\section{Study area and data sources}

In this study, the area controlled by the Xianyang hydrological station of the Weihe River was selected as the study area (see in Fig. 1). The river is $610 \mathrm{~km}$ long with a watershed area of $46827 \mathrm{~km}^{2}$, the largest tributary of the Yellow River. The elevation ranges from a minimum of $400 \mathrm{~m}$ to a maximum of $3145 \mathrm{~m}$ (the average elevation is $1695 \mathrm{~m}$ ). The basin is characterized by a typical temperate continental climate, with a mean annual precipitation of $551 \mathrm{~mm}$. The multiannual natural discharge of the basin is $38.1 \times 10^{8} \mathrm{~m}^{3}$. The Weihe River basin is a typical droughtprone area, with four drying-up (zero streamflow) events occurring during the 20th century.

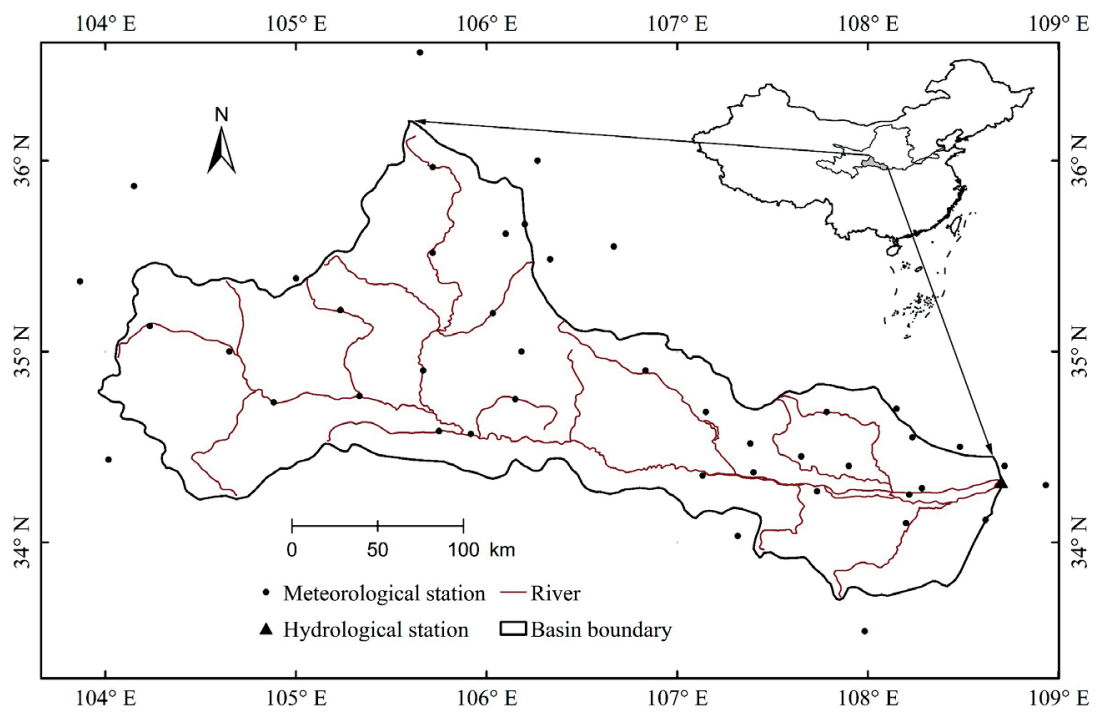

Fig. 1 Location of the Weihe River basin with meteorological and hydrological stations.

Weather data at 44 meteorological stations within and around the Weihe River basin, including daily precipitation, wind velocity, maximum and minimum air temperature, were provided by National Climate Center, China Meteorological Administration. The daily runoff data at the Xianyang hydrological station were provided by Ministry of Water Resources of China. The daily meteorological observations from 1961 to 2012 were interpolated onto each 544 grid-cell $\left(0.1^{\circ} \times 0.1^{\circ}\right)$ using the inverse distance weighted method (the exponent of distance is taken as 2 in this study). In addition, VIC requires three GIS data layers: digital elevation model (DEM), soil properties and land use. The DEM with a resolution of $1 \mathrm{~km}$ was provided by the National Geophysical Data Center of NOAA. The global 1-km land cover classification dataset developed by Maryland University and global $10-\mathrm{km}$ soil profile dataset provided by Food and Agriculture Organization (FAO) were used in this study.

\section{VIC runoff simulation}

The VIC model is a macroscale distributed hydrological model that combines both water and energy balances (Liang, 1994). VIC has been widely used in large-scale drought assessment recently. In this study, version 4.1.2 of VIC is used to reconstruct monthly runoff from 1961 to 2012. This version is the latest release that uses the new surface runoff parameterization described in Liang et al. (2003). The Weihe River basin was divided into 544 grid cells with a resolution of $0.1^{\circ} \times 0.1^{\circ}$, then VIC was run at each grid to simulate the water balance and the Muskingum method was applied for river flow concentration calculation. Finally, the observed and simulated daily hydrographs at the Xianyang hydrological station were used for model calibration and validation. 
The performance of VIC in simulating discharge was quantified by the Nash-Sutcliffe model efficiency coefficient $\left(E_{N S}\right)$ and the relative error $\left(E_{r}\right)$ between multiannual observations and simulations. Based on these two optimization objective functions, we can get the best establishment of VIC for those two periods in the Weihe River basin and then get the gridded monthly runoff for 1961 to 2012.

\section{The modified Standardized Runoff Index}

The Standardized Runoff Index (SRI) was developed by Shukla and Wood (2008), and incorporates hydrologic processes and employs the algorithm of standardized index (SI). The SRI is based on the monthly mean runoff $\bar{r}$, letting the aggregated values $R_{w}(t)=\sum_{t-w+1}^{t} \bar{r}_{i}(t$ represents the end month and $w$ is the time scale) indicate the total $\bar{r}$ for a given $w$-month window with respect to $t$. Then the marginal cumulative distribution function (CDF) is obtained by fitting the whole series to an appropriate empirical distribution function. However, there are some flaws in the conventional SRI algorithm in that significant autocorrelation may exist in the runoff series and lead to biased distribution fitting (Kao et al., 2010). The seasonal variability of runoff should be considered. In this study, 12 runoff series for each monthly runoff series were constructed according to the ending month and were fitted respectively, in order to consider the seasonal variation of SRI.

Table 1 shows the weather classification according to SRI, and those standards are defined by the non-exceedence probability related to SRI values. The probabilities $\Delta P$ lying within each class are also listed.

Table 1 Wet and drought period classification based on SRI.

\begin{tabular}{llll}
\hline SRI values & Class & Probability & $\Delta P$ \\
\hline$[2,+\infty)$ & Extremely wet & {$[0.000,0.003)$} & 0.003 \\
{$[1.5,2.0)$} & Very wet & {$[0.003,0.037)$} & 0.034 \\
{$[1.0,1.5)$} & Moderately wet & {$[0.037,0.161)$} & 0.124 \\
$(-1.0,1.0)$ & Near normal & $(0.161,0.852)$ & 0.691 \\
$(-1.5,-1.0)]$ & Moderately drought & $(0.852,0.919]$ & 0.067 \\
$(-2.0,-1.5]$ & Severely drought & $(0.919,0.962]$ & 0.043 \\
$(-\infty,-2.0]$ & Extremely drought & $(0.962,1.000]$ & 0.038 \\
\hline
\end{tabular}

\section{RESULTS AND DISCUSSION}

\section{Verification of VIC model}

The Mann-Kendall test was used for streamflow trend analysis and identified an abrupt decrease of the natural discharge since 1990 (see in Fig. 2). This change point made the two periods (19611989 and 1990-2012) quite different in their statistical characteristics, and thus the data no longer meets the data homogeneity criteria in hydrological modelling. Therefore, a staging model verification scheme was proposed in this study. The data series of 1961 to 2012 was divided into two periods by 1990, and the model verification was implemented in each period independently. The results of VIC calibration and validation using daily discharge records at the Xianyang hydrological station are presented in Table 2. The values of $E_{N S}$-daily and $E_{N S}$-monthly were all greater than 0.6 except for Stage 2 validation and the values of $E_{r}$ for each period were less than $15 \%$, which indicated a good match between the simulated and observed hydrographs (Fig. 2). The results showed that the verification scheme was effective to deal with this situation and could realistically describe the hydrological processes, implying that the VIC model was applicable to the Weihe River basin. 


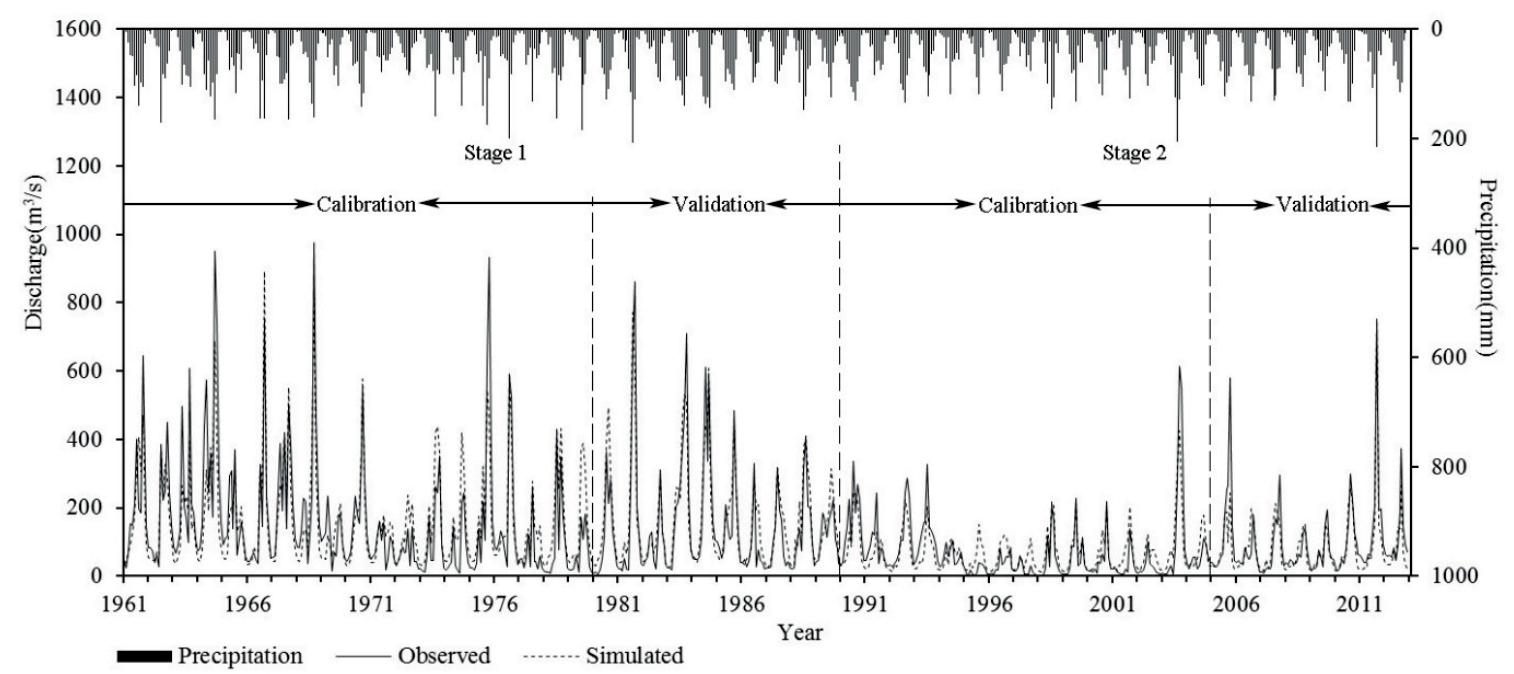

Fig. 2 Comparison of VIC-simulated and observed hydrograph at the Xianyang hydrological station.

Table 2 Results of the VIC staging calibration and validation.

\begin{tabular}{llllr}
\hline & Period & $E_{N S}$-daily & $E_{N S}$-monthly & $E_{r}(\%)$ \\
\hline \multirow{2}{*}{ Stage1 } & Calibration(1961-1980) & 0.69 & 0.72 & 3.4 \\
& Validation(1981-1989) & 0.79 & 0.85 & 10.2 \\
\multirow{2}{*}{ Stage2 } & Calibration(1990-2004) & 0.61 & 0.68 & 4.3 \\
& Validation(2005-2012) & 0.55 & 0.76 & -12.0 \\
\hline
\end{tabular}

\section{Spatio-temporal characteristics of droughts in the Weihe River basin}

In this section, the VIC-simulated gridded runoff series at 0.1-degree resolution were applied to compute the modified SRI for regional drought assessment in the Weihe River basin.

\section{Temporal variation}

The annual drought area ratio, based on the gridded SRI, gives a comprehensive reflection of regional droughts, and is especially useful for large-scale drought events. In this study, the drought area ratio (the drought area divided by the total) based on SRI-3 and SRI-12 were analysed. As shown in Fig. 3, both the red and blue dash lines indicate severe droughts in the early 1970s, late 1980s and 1990s, respectively. The 5-year moving average lines show obvious upward trends in the 1970s and 1990s. Due to a significant drop in runoff in the 1990s (Fig. 2), a decadal fluctuation of drought area and continuous severe droughts occurred in the same period.

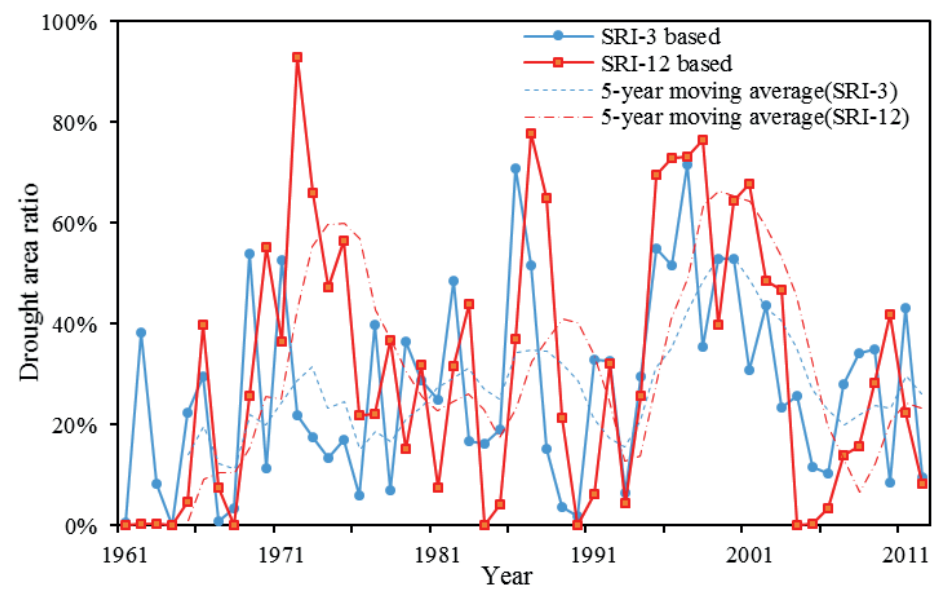

Fig. 3 Drought area ratio from 1961 to 2012, based on 3- and 12-month gridded SRI. 


\section{Drought spatial distribution}

Due to the variability of hydrometeorological conditions and the underlying land cover inhomogeneity, regional drought characteristics vary spatially. The decadal drought frequency distributions are shown in Fig. 4. It is obvious that drought in the Weihe River basin has become more frequent since the 1960s and reached a very severe situation in the 1970s when the frequency over the whole basin was higher than $40 \%$, especially in the northern, southeastern and middle parts with a frequency greater than 60\%. This drought situation alleviated in 1980 s with an average frequency of $30 \%$. However, the central and western parts suffered long-term droughts in 1990s. There are a series of persistent droughts in the 1990s along with two extreme drought events in 1991 and 1997. In the early 21 st century, the drought centre moved to the northern part and the frequency values in most areas were below $40 \%$.

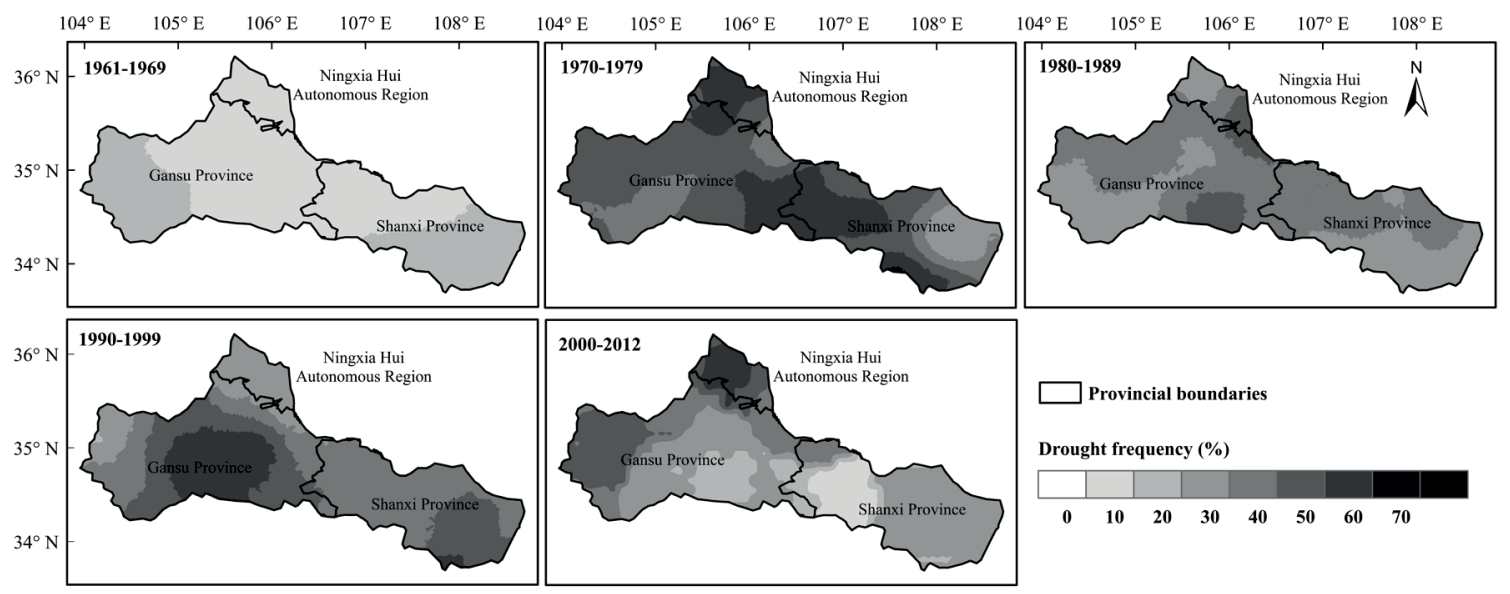

Fig. 4 Decadal drought frequency map of the Weihe River basin, based on gridded SRI-12.

Meanwhile, Fig. 4 shows that the western and northern parts of the Weihe River basin (the source areas of the Weihe River), are drought-prone areas. Specifically, in the 1990s the Huluhe River, one of the largest tributaries of the Weihe River, originating from the west of the basin, has experienced more than 560 days of drying-up. The severe droughts in 1997 and 1998 resulted in a period of 108 and 154 days, respectively, with no streamflow in the Huluhe River, along with the longest consecutive drying-up of 35 and 36 days, respectively. These severe droughts caused large economic and societal losses to Guanzhong region, which is a populated area with a relatively well developed economy in northwestern China.

\section{CONCLUSION}

This study was focused on reconstructing physically-based and multi-temporal standardized runoff index series for evaluating regional droughts in the Weihe River basin. The major conclusions are listed below.

(a) VIC is applicable for hydrological modelling in the Weihe River basin.

(b) Spatial and temporal variations were analysed using gridded SRI series. Both of them represent wet/dry season alternating phenomena among the decades. It was also found that the north and the west parts are drought-prone areas with severe droughts in almost all the decades.

(c) The coupled VIC-SRI model could give physically-based and rational spatio-temporal drought evolutions. It is applicable for real-time drought monitoring, forecasting and early warning. 
Acknowledgements This work was financially supported by the national key technology R\&D program of China (grant 2013BAC10B02). The authors would like to express their appreciation for the grants received to aid this research.

\section{REFERENCES}

Bai, H.Z. (2010) Yearly Charts of Dryness/Wetness in Northwest China for the Last 500 Years Period (1470-2008). Beijing: China Meteorological Press.

Bai, H.Z. (2011) Extreme droughts in Northwest China for the Last 500 Years Period (1470-2008). Beijing: China Meteorological Press.

Kao, S.C. and Govindaraju, R.S. (2010). A copula-based joint deficit index for droughts. Journal of Hydrology 380(1), 121-134.

Liang. X. (1994) A simple hydrologically based model of land surface water and energy fluxes for general circulation models. Journal of Geophysical Research 99(7), 14415-14428.

Liang, X., Xie, Z. and Huang. M. (2003) A new parameterization for surface and groundwater interactions and its impact on water budgets with the variable infiltration capacity (VIC) land surface model. Journal of Geophysical Research: Atmospheres (1984-2012), 108(D16).

McKee. T. B.. Doesken. N. J. and Kleist. J. (1993) The relationship of drought frequency and duration to time scales. In Proceedings of the 8th Conference on Applied Climatology (vol. 17, 179-183). Boston, MA: American Meteorological Society.

Mo, K.C. (2008) Model-based drought indices over the United States. Journal of Hydrometeorology 9(6), 1212-1230.

Shukla, S. and Wood, A. W. (2008) Use of a standardized runoff index for characterizing hydrologic drought. Geophysical Research Letters 35(2).

Wilhite, D.A. (2000) Drought as a natural hazard: concepts and definitions. Drought, A Global Assessment 1, 3-18.

Yevjevich, V. (1967). An obiective approach to definitions and investigations of continental hydrologic droughts. Fort Collins: Colorado State University.

Yuan. W.P. and Zhou, G.S. (2004). Theoretical study and research prospect on drought indices. Advances in Earth Science. 19(6), 982-991.

Zargar, A., et al. (2011). A review of drought indices. Environmental Reviews 19(NA), 333-349. 